\title{
Pengembangan LKPD Terintegrasi STEM-PjBL (Science, Technology, Engineering, and Mathematics- Project Based Learning) pada Materi Termokimia
}

\section{LKPD Development STEM-PjBL (Science, Technology, Engineering, and Mathematics-Project Based Learning) Integrated on Thermochemical Learning}

\author{
S S Syafe' $\mathbf{i}^{1}$ and Effendi ${ }^{1^{*}}$ \\ ${ }^{1}$ Pendidikan Kimia, Universitas Negeri Padang, Jl. Prof. Dr. Hamka, Air Tawar Barat, \\ Padang Utara, Sumatera Barat, Indonesia 25171 \\ *fernando00id@yahoo.com
}

\section{ARTICLE INFO}

Received 20 January 2020

Revised 03 February 2020

Published 18 May 2020

\begin{abstract}
This research produce LKPD STEM-PjBL (Science, Technology, Engineering, and Mathematics-Project Based Learning) integrated on Thermochemical learning, then reveal its validity and practicality categories. This type of research is $R \& D$ (Research and Development), with 4-D model consisting of: (1) define, (2) design, (3) develop, and (4) disseminate. LKPD was validated by 3 Chemistry lecturers of FMIPA UNP and 2 Chemistry teachers, then practicality test done by 2 Chemistry teachers and 25 students of Class XII MIA 2 SMA UNP Laboratory Development. The validity and practicality tests were using Cohen's kappa analysed, yielding 0.816 for the validity test and 0.837 and 0.855 for the teacher and student practicality test with very high categories. The data shows that the LKPD produced is valid and practical.
\end{abstract}

\section{KEYWORDS}

STEM-PjBL, Student Worksheet, Thermochemical, R\&D, 4-D Model

\begin{abstract}
ABSTRAK
Penelitian yang telah dilaksanakan menghasilkan LKPD terintegrasi STEM-PjBL (Science, Technology, Engineering, and Mathematics-Project Based Learning) pada materi Termokimia, kemudian mengungkapkan kategori validitas dan praktikalitasnya. Penelitian yang dilakukan merupakan penelitian $\mathrm{R} \& \mathrm{D}$ (Research and Development), dengan model 4-D yang terdiri dari: (1) define, (2) design, (3) develop, dan (4) disseminate. LKPD divalidasi oleh 3 orang dosen Kimia FMIPA UNP dan 2 orang guru Kimia, sedangkan uji praktikalitas oleh 2 orang guru kimia dan 25 orang siswa kelas XII MIA 2 SMA Pembangunan Laboratorium UNP. Uji validitas dan praktikalitas dianalisis dengan formula kappa Cohen, menghasilkan 0,816 untuk uji validitas, serta 0,837 dan 0,855 untuk uji praktikalitas guru dan peserta didik, memiliki kategori sangat tinggi. Data menunjukkan bahwa LKPD yang dihasilkan valid dan praktis.
\end{abstract}

KATA KUNCI

STEM-PjBL, LKPD, Termokimia, R\&D, Model 4-D 


\section{PENDAHULUAN}

Tujuan dari pendidikan nasional selain mengharapkan peserta didik memiliki ilmu pengetahuan, juga mengharapkan peserta didik untuk memperoleh keterampilan, pengembangan sikap, serta pengalaman belajar agar mampu berpikir secara logis, kritis dan kreatif sehingga dapat mengaplikasikannya pada kehidupan seharihari ${ }^{[1]}$. Tujuan pendidikan nasional tersebut dapat diwujudkan melalui pendekatan STEM.

STEM (Science, Technology, Engineering and Mathematics) merupakan pendekatan interdisipliner dalam pembelajaran, yang di dalamnya memuat ilmu sains, teknologi, teknik, dan matematika. Memfokuskan empat bidang utama tersebut dalam pembelajaran, diharapkan mampu meningkatkan kemampuan 4C (creativity, critical thinking, collaboration, and communication) peserta didik $^{[2]}$. Selain itu juga memberi pengalaman kepada peserta didik dalam melakukan proses rekayasa (Engineering), dan membantu meningkatkan prestasi pada saat ujian akhir sekolah ${ }^{[3]}$.

PjBL (Project Based Learning) adalah salah satu model pembelajaran yang disarankan kurikulum 2013 dengan melibatkan proyek serta proses rekayasa dalam pembelajaran. PjBL memiliki enam tahapan dalam penerapannya yaitu: (1) penyajian masalah; (2) pembuatan rencana; (3) penyusunan jadwal; (4) memonitor pembuatan proyek; (5) pelaksanaan penilaian; (6) evaluasi ${ }^{[4]}$.

Kolaborasi antara PjBL dengan STEM mampu meningkatkan efektivitas ${ }^{[5]}$ dan motivasi, menimbulkan ketertarikan dalam memahami materi, serta mampu membentuk sikap kreatif $f^{[6]}$. Selain itu STEM-PjBL juga mampu meningkatkan kemampuan dalam bereksplorasi, membuat perencanaan kegiatan pembelajaran, pelaksanaan proyek secara kolaboratif, hingga mampu menghasilkan produk mini dalam pembelajaran ${ }^{[7]}$.

Termokimia adalah suatu materi yang diajarkan di kelas XI SMA/MA. Berdasarkan analisis kurikulum 2013 revisi 2018, materi termokimia memiliki empat dimensi pengetahuan. Menurut Trianto dimensi pengetahuan tersebut terdiri atas: fakta, konsep, prinsip dan prosedur ${ }^{[8]}$. Berdasarkan hal tersebut maka STEM-PjBL sangat pas diterapkan pada materi Termokimia, dan akan lebih bagus lagi apabila diwujudkan dalam suatu bahan ajar berupa LKPD.

LKPD (Lembar Kerja Peserta Didik) memuat lembaran-lembaran tugas yang harus diselesaikan oleh peserta didik. Istilah LKPD (Lembar Kerja Peserta Didik) berasal dari LKS (Lembar Kerja Siswa), yang disesuaikan berdasarkan perubahan istilah siswa menjadi peserta didik pada penerapan Kurikulum 2013. Tujuan bahan ajar LKPD adalah memberikan bantuan kepada peserta didik dalam menemukan konsep, penguatan/pemantapan konsep, penentuan belajar, dan petunjuk praktikum ${ }^{[9]}$. LKPD terintegrasi STEM-PjBL mengharapkan peserta didik terbantu dalam pemantapan dan pemahaman konsep dengan baik.
Melalui hasil analisis angket yang diserahkan kepada peserta didik serta hasil analisis wawancara bersama guru SMAN 2 Padang, SMAN 3 Sijunjung dan SMA Pembangunan Laboratorium UNP, diperoleh kesimpulan bahwa secara keseluruhan peserta didik beranggapan materi Termokimia adalah materi yang sulit dipahami dan kurang menarik untuk dipelajari. Kemudian bahan ajar yang digunakan guru selain buku teks, sudah dibantu dengan LKPD. Akan tetapi, LKPD yang digunakan tidak berwarna, banyak teks, dan sedikit gambar. Selain itu LKPD yang tersedia belum terintegrasi STEM-PjBL yang menuntun peserta didik menghasilkan proyek sederhana serta mampu mengembangkan kemampuan 4-C yaitu (Creativity, Critical thinking, Collaboration, and Communication), peserta didik dalam pembelajaran.

Berdasarkan penelitian relevan terkait pengembangan LKPD terintegrasi STEM-PjBL didapati bahwa, secara keseluruhan baik peserta didik laki-laki maupun perempuan merasa pembelajaran dengan STEM-PjBL sangat menyenangkan. Tidak hanya itu, peserta didik juga memperoleh pengalaman berkesan dalam pembelajaran sehingga mampu memicu motivasi dan minat belajar pada peserta didik ${ }^{[1]}$. LKS berpendekatan STEM juga mampu memberikan peningkatan pada kemampuan peserta didik dalam berpikir kritis di kelas VIII SMP ${ }^{10]}$. Serta pembelajaran dengan model PjBL berpendekatan STEM dianggap sesuai direalisasikan dalam suatu bentuk bahan ajar berupa LKPD ${ }^{[1]}$.

Berdasarkan hal di atas penulis memiliki ketertarikan dalam mengembangkan bahan ajar LKPD ayang terintegrasi STEM-PjBL (Science, Technology, Engineering, and Mathematics-Project Based Learning) untuk materi Termokimia.

\section{METODE}

Penelitian yang dilakukan menggunakan jenis penelitian dan pengembangan, Research and Development (R\&D). Penelitian R\&D akan menghasilkan suatu produk tertentu dan dilanjutkan dengan pengujian efektivitas terhadap produk tersebut ${ }^{[12]}$. Produk yang dihasilkan berupa LKPD terintegrasi STEM-PjBL (Science, Technology, Engineering, and Mathematics-Project Based Learning) pada materi Termokimia. Model yang digunakan pada pengembangan LKPD yaitu model 4-D (four $D$ models) yang terdiri dari: (1) Define (pendefinisian); (2) Design (perancangan); (3) Develop (pengembangan); dan (4) Disseminate (penyebaran) ${ }^{[13]}$.

Tahap define (pendefinisian) dilakukan untuk menganalisis kesulitan dan kendala yang dialami dalam pembelajaran. Hasil dari analisis tersebut digunakan dalam penentuan dan penetapan syarat-syarat yang dibutuhkan pada proses pembelajaran. Pada tahap ini terdapat 5 pokok kegiatan, yaitu analisis ujung depan, analisis peserta didik, analisis tugas, analisis konsep, dan perumusan tujuan pembelajaran. 
Tahap design (perancangan) merupakan tahapan yang bertujuan untuk merancang suatu bahan ajar berupa LKPD terintegrasi STEM-PjBL (Science, Technology, Engineering and MathematicsProject Based Learning) pada materi Termokimia. LKPD ini dirancang berdasarkan susunannya yaitu: judul, daftar isi, profil LKPD, petunjuk penggunaan, standar kompetensi lulusan, langkah-langkah model pembelajaran, soal evaluasi, dan penilaian.

Tahap develop (pengembangan) bertujuan untuk menghasilkan LKPD terintegrasi STEM-PjBL (Science, Technology, Engineering and MathematicsProject Based Learning) pada materi Termokimia yang telah valid dan praktis agar dapat diterapkan pada proses pembelajaran. Pada tahap ini dilakukan tiga proses yaitu, uji kevalidan produk, revisi produk hasil validasi, dan uji praktikalitas produk.

Instrumen yang digunakan pada penelitian ini yaitu angket validasi dan praktikalitas, dan hasil dari analisis tersebut diolah menggunakan formula kappa Cohen:

$$
\text { momen kappa }(k)=\frac{\rho_{0}-\rho_{e}}{1-\rho_{e}}
$$

$k=$ nilai momen kappa

$\rho_{0}=$ proporsi yang tidak terealisasi

$\rho_{e}=$ proporsi yang terealisasi

Tabel 1. Kategori Keputusan berdasarkan Momen kappa $(k)$.

\begin{tabular}{c|c} 
Interval & Kategori \\
\hline$<0,00$ & Tidak Valid \\
\hline $0,00-0,20$ & Sangat Rendah \\
\hline $0,21-0,40$ & Rendah \\
\hline $0,41-0,60$ & Sedang \\
\hline $0,61-0,80$ & Tinggi \\
\hline $0,81-1,00$ & Sangat Tinggi
\end{tabular}

\section{HASIL DAN DISKUSI}

Penelitian dilakukan dengan metode $R \& D$ (Research and Development) menggunakan model pengembangan 4-D yang terdiri dari define (pendefinisian), design (perancangan), develop (pengembangan), dan disseminate (penyebaran) ${ }^{[13]}$. Produk yang dihasilkan berupa LKPD terintegrasi STEM-PjBL (Science, Technology, Engineering, and Mathematics-Project Based Learning) pada materi Termokimia. Penelitian dilakukan melalui uji validitas oleh dosen kimia FMIPA UNP dan guru kimia SMA, dilanjutkan dengan revisi, serta uji praktikalitas oleh guru kimia SMA dan peserta didik kelas XI MIA. Hasil penelitian secara keseluruhan diperoleh berupa:

\subsection{Tahap Define (Pendefinisian)}

Tahap define menghasilkan 5 data yang diperoleh berdasarkan analisis ujung depan, analisis peserta didik, analisis tugas, analisis konsep, dan perumusan tujuan pembelajaran:

\subsubsection{Analisis Ujung Depan}

Melalui wawancara yang telah dilakukan dengan guru dan serta angket yang telah diisi oleh peserta didik, dihasilkan bahwa: (1) Belum adanya penerapan model $\mathrm{PjBL}$ dalam pembelajaran; (2) masih adanya sekolah yang belum melaksanakan praktikum; (3) LKPD yang digunakan tidak berwarna, memuat banyak teks dan sedikit gambar; dan (4) belum tersedianya LKPD yang mampu meningkatkan kemampuan 4C (Creativity, Communication, Collaboration and Critical Thinking) peserta didik.

\subsubsection{Analisis Peserta Didik}

Melalui analisis yang telah dilakukan terhadap peserta didik, diperoleh bahwa:(1) analisis dilakukan pada peserta didik dengan usia 15-17 tahun; (2) $55 \%$ peserta didik menyatakan bahwa pembelajaran Termokimia kurang menarik, dan sulit dipahami; (3) $63 \%$ peserta didik tertarik dengan LKPD bergambar dan berwarna; (4) hanya sebagian kecil peserta didik yang mampu menjawab pertanyaan atau soal-soal pada materi Termokimia; dan (5) kurangnya semangat peserta didik saat pelaksanaan praktikum karena praktikum yang kurang menarik.

\subsubsection{Analisis Tugas}

Analisis tugas dilakukan dengan cara menganalisis KD (Kompetensi Dasar), kemudian diturunkan menjadi IPK (Indeks Pencapaian Kompetensi), dan tujuan pembelajaran yang diwajibkan tercapai oleh peserta didik pada pembelajaran. Adapun kompetensi dasar untuk materi Termokimia terdiri dari: 3.4. Menjelaskan konsep perubahan entalpi reaksi pada tekanan tetap dalam persamaan Termokimia; 3.5. Menjelaskan jenis entalpi reaksi, hukum Hess dan konsep energi ikatan; 4.4. Menyimpulkan hasil analisis data percobaan termokimia pada tekanan tetap; 4.5. Membandingkan perubahan entalpi beberapa reaksi berdasarkan data hasil percobaan. $\mathrm{KD}$ tersebut diturunkan menjadi beberapa IPK yaitu: 3.4.1. Mengidentifikasi sistem dan lingkungan; 3.4.2. Menentukan reaksi eksoterm dan reaksi endoterm; 3.4.3. Menggambarkan diagram tingkat energi berdasarkan reaksi eksoterm dan/atau reaksi endoterm yang terjadi pada suatu reaksi; 3.4.4. Menuliskan persamaan reaksi Termokimia; 3.5.1. Mengidentifikasi jenis-jenis perubahan entalpi standar untuk berbagai reaksi; 3.5.2. Menghitung harga $\Delta \mathrm{H}$ reaksi secara sederhana menggunakan kalorimeter; 3.5.3. Menghitung harga $\Delta \mathrm{H}$ reaksi berdasarkan konsep hukum Hess; 3.5.4. Menghitung harga $\Delta \mathrm{H}$ reaksi berdasarkan konsep energi ikatan; 4.4.1. Menyimpulkan hasil analisis data percobaan dalam pembelajaran proyek Termokimia 
pada tekanan tetap; 4.5.1. Membandingkan $\Delta \mathrm{H}$ beberapa reaksi berdasarkan data hasil percobaan.

\subsubsection{Analisis Konsep}

Tahap ini menghasilkan; (1) Analisis materi yang diperoleh berdasarkan dimensi pengetahuan berupa fakta, konsep, prinsip dan prosedur; (2) Analisis konsep, yang dibagi atas label konsep, definisi konsep, atribut konsep, hierarki konsep, jenis konsep, contoh, dan non contoh hingga disusun menjadi peta konsep.

\subsubsection{Perumusan Tujuan Pembelajaran}

Tujuan pembelajaran pada materi Termokimia yang telah dirumuskan melalui pendekatan STEM dengan model pembelajaran $\mathrm{PjBL}$ yang terintegrasi menjadi STEM-PjBL dengan mencari dan memperoleh informasi berdasarkan sumbersumber belajar, menyelidiki secara sederhana, dan melakukan pengolahan informasi, diharapkan peserta didik akan aktif dalam proses pembelajaran, meningkatkan sikap keingintahuan, lebih teliti saat pelaksanaan pengamatan, dan bertanggung jawab terhadap pendapat yang dikemukakan, menjawab pertanyaan, memberikan kritik dan saran, serta mampu mencapai IPK yang diharapkan.

\subsection{Tahap Design (Perancangan)}

Tahap design (perancangan) menghasilkan rancangan awal yang didasarkan pada tahap define. Format penulisan rancangan awal LKPD terintegrasi STEM-PjBL didasarkan pada buku panduan pengembangan bahan ajar yaitu terdiri atas cover, halaman pendukung (kata pengantar, daftar isi, tata tertib, simbol bahan berbahaya, alat-alat laboratorium kimia, dan kepustakaan), petunjuk penggunaan LKPD, kompetensi yang perlu dicapai (KI, KD, IPK dan Tujuan Pembelajaran), informasi pendukung (ringkasan materi yang diperlukan), tugas-tugas dan langkah-langkah kerja, dan penilaian. Pembuatan LKPD diproses dengan Microsoft Word 2016, Adobe Photoshop CS5, Snipping Tool, dan Microsoft Publisher 2016, hingga dihasilkan LKPD yang menarik dan sesuai harapan.

\subsection{Tahap Pengembangan (Develop)}

\subsubsection{Uji Validitas}

Pelaksanaan uji validitas berdasarkan penilaian menurut Depdiknas terdiri atas empat komponen uji yaitu: komponen kelayakan isi, komponen kebahasaan, komponen penyajian, dan komponen kegrafikan $^{[14]}$. Uji kevalidan dilakukan oleh 3 orang dosen kimia FMIPA UNP dan 2 orang guru kimia SMA. Pengujian validitas oleh 5 orang validator dilakukan berdasarkan pendapat ahli (judgment experts) dengan jumlah minimal 3 orang ${ }^{[12]}$. Berdasarkan penilai tersebut, dilakukan pengolahan data dengan formula kappa Cohen. Informasi dapat dilihat pada Gambar 1.

\section{Hasil Uji Validitas \\ LKPD terintegrasi STEM-PjBL pada Materi Termokimia}

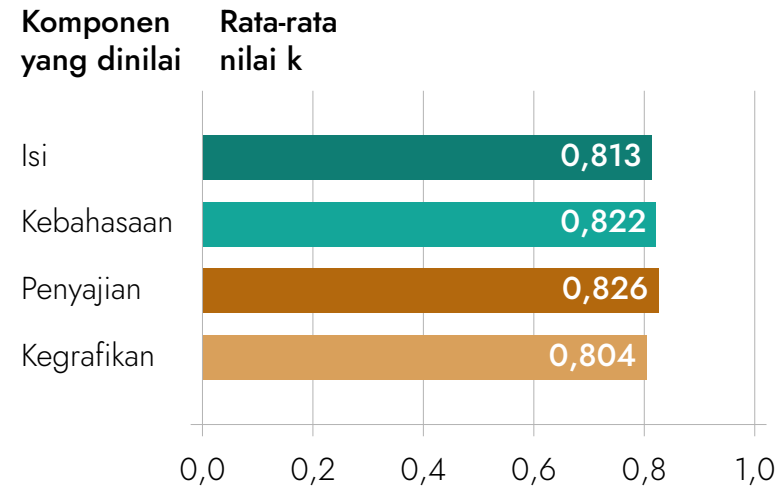

Gambar 1. Grafik Hasil Uji Validitas.

Berdasarkan grafik di atas diperoleh rata-rata momen kappa pada komponen kelayakan isi sebesar 0,813 dengan kategori sangat tinggi. Penilaian yang dilakukan tersebut merupakan penilaian terkait kesesuaian isi LKPD terhadap materi Termokimia. Nilai kappa yang dihasilkan berarti bahwa LKPD Termokimia terintegrasi STEM-PjBL telah menyesuaikan dengan tuntutan kurikulum 2013 revisi 2017. Sehingga LKPD dinyatakan valid karena telah menyesuaikan dengan tuntutan kurikulum.

Penilaian komponen kebahasaan LKPD menghasilkan rata-rata momen kappa dengan nilai sebesar 0,822 pada kategori sangat tinggi. Aspek penilaian komponen kebahasaan berdasarkan panduan bahan ajar ${ }^{[14]}$ meliputi: keterbacaan, kejelasan informasi kesesuaian dengan kaidah bahasa Indonesia yang benar.

Perolehan nilai rata-rata momen kappa komponen penyajian adalah sebesar 0,826 dengan kategori validitas sangat tinggi. Hal ini menunjukkan bahwa LKPD yang dihasilkan telah sesuai dengan IPK dan urutan penyajian materi berdasarkan model PjBL yang digunakan yang terdiri dari: (1) penyajian masalah; (2) merencanakan dan menjadwalkan proyek; (3) membuat proyek; (4) menilai; dan (5) mengevaluasi proyek ${ }^{[4]}$.

Selanjutnya penilaian komponen kegrafikan dari produk yang dikembangkan, menghasilkan momen kappa dengan nilai sebesar 0,804, pada kategori tinggi. Hal ini berarti tata letak (layout), jenis dan ukuran huruf, kejelasan gambar, serta pemilihan warna dari LKPD dinilai menarik secara keseluruhan. Keteraturan dan kesesuaian tata letak dan warna yang baik mampu menimbulkan daya tarik serta minat belajar pada peserta didik ${ }^{[15]}$.

\subsubsection{Revisi}

Tahap revisi bertujuan untuk memperbaiki bagian LKPD terintegrasi STEM-PjBL pada materi Termokimia yang dianggap belum sesuai oleh validator sebelum akhirnya dilakukan uji coba terhadap produk yang dihasilkan. Revisi dinyatakan selesai ketika LKPD yang dikembangkan dianggap telah valid oleh validator. 


\section{Hasil Uji Praktikalitas LKPD terintegrasi STEM-PjBL pada Materi Termokimia}
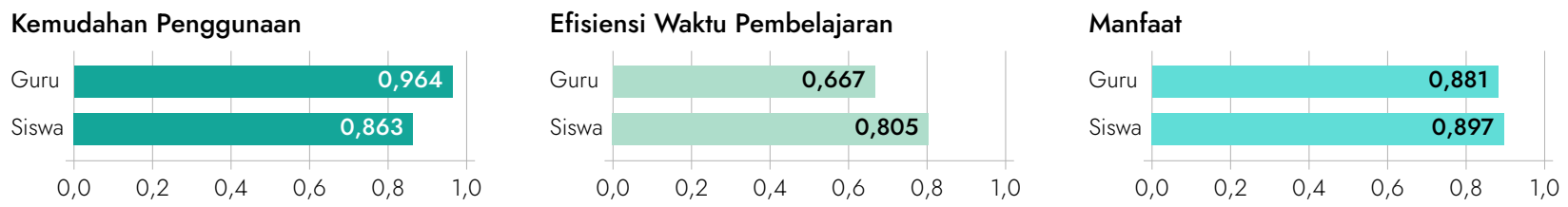

Gambar 2. Grafik Hasil Uji Praktikalitas.

\subsubsection{Uji Praktikalitas}

Kepraktisan LKPD terintegrasi STEM-PjBL (Science, Technology, Engineering, and MathematicsProject Based Learning) pada materi Termokimia yang dikembangkan terlihat pada penggunaan produk pada hasil uji coba terbatas di lapangan. Uji praktikalitas dilaksanakan kepada guru dan peserta didik. Informasi dapat dilihat pada Gambar 2.

Berdasarkan penilaian guru dan peserta didik yang dapat dilihat pada grafik di atas terhadap kemudahan penggunaan, diperoleh bahwa LKPD yang dikembangkan sangat praktis pada kategori praktikalitas sangat tinggi dan perolehan momen kappa senilai 0,964 (guru) dan 0,863 (peserta didik). Nilai kappa yang diperoleh menunjukkan bahwa LKPD disampaikan secara sederhana sehingga mudah dipahami oleh guru dan peserta didik, langkah pembelajaran yang jelas sesuai dengan model pembelajaran Project Based Learning (PjBL).

Komponen efisiensi waktu memiliki rata-rata momen kappa dari guru dan peserta didik senilai 0,805 dan 0,667 pada kategori kepraktisan tinggi. Lembar kerja yang terdapat pada LKPD mampu membantu peserta didik dalam pembelajaran, seperti meningkatkan pemahaman, memperoleh keterampilan, serta pengembangan sikap yang baik. Selain itu, penggunaan lembaran kerja juga mampu mengarahkan pembelajaran agar lebih efektif dan efisien $^{[16]}$. Nilai kappa yang diperoleh memberi pernyataan terhadap LKPD yang dikembangkan, bahwa LKPD telah efisien untuk digunakan dalam kegiatan belajar.

Komponen manfaat penggunaan LKPD memiliki rata-rata momen kappa berdasarkan angket yang direspon oleh guru dan peserta didik senilai 0,881 dan 0,897 pada kategori kepraktisan sangat tinggi. Hal ini menyatakan bahwa LKPD memberikan manfaat bagi guru maupun peserta didik. Manfaat bagi guru salah satunya meningkatkan peran guru sebagai fasilitator. LKPD dapat memantau dan menilai kinerja kelompok serta memperoleh informasi tentang pemahaman peserta didik melalui keaktifannya dalam proses pembelajaran. Manfaat yang diperoleh peserta didik diantaranya meningkatkan minat peserta didik yaitu mampu membantu peserta didik untuk saling berkolaborasi, berkomunikasi, meningkatkan kreativitas, kemampuan berpikir kritis. Terpenting yaitu membantu menuntun peserta didik agar memperoleh suatu produk mini.

\section{SIMPULAN}

Berdasarkan penelitian yang telah dilakukan, dapat disimpulkan bahwa:

1. LKPD terintegrasi STEM-PjBL (Science, Technology, Engineering, and MathematicsProject Based Learning) pada materi Termokimia memiliki tingkat validitas senilai 0,816 pada kategori sangat tinggi, hal ini menyatakan bahwa LKPD yang dikembangkan telah valid.

2. LKPD terintegrasi STEM-PjBL (Science, Technology, Engineering, and MathematicsProject Based Learning) pada materi Termokimia memiliki tingkat praktikalitas guru dan peserta didik 0,837 dan 0,855 dengan kategori kepraktisan sangat tinggi, hal ini menyatakan bahwa LKPD yang dikembangkan praktis untuk digunakan dalam pembelajaran.

\section{REFERENSI}

1. Kementerian Pendidikan dan Kebudayaan. Peraturan Menteri Pendidikan dan Kebudayaan Republik Indonesia Nomor 54 Tahun 2013 tentang Standar Kompetensi Lulusan Pendidikan Dasar dan Menengah. Jakarta: Kemendikbud; 2013.

2. $\quad$ Beers SZ. 21st Century Skills. 2014;1-6.

3. Suwarma IR, Astuti P, Endah EN. Baloon powered car sebagai media pembelajaran IPA berbasis STEM (Science, Technology, Engineering, and Mathematics).

4. Sani RA. Pembelajaran Saintifik untuk Implementasi Kurikulum 2013. Jakarta: PT. Bumi Aksara; 2018.

5. Tseng KH, Chang CC, Lou SI, Chen WP. Attitudes towards Science, Technology, Engineering and Mathematics (STEM) in a Project-Based Learning (PjBL) environment. Int I Technol Des Educ 2013;23(1):87-102.

6. Afriana I, Permanasari A, Fitriani A. Penerapan Project Based Learning Terintegrasi STEM untuk Meningkatkan Literasi Sains Siswa Ditinjau Dari Gender. J Inov Pendidik IPA 2016;2(2):202-12.

7. Jauhariyyah FR, Suwono H, Ibrohim. Science, Technology, Engineering and Mathematics Project Based Learning (STEM-PjBL) pada Pembelajaran Sains. In: Seminar Nasional Pendidikan IPA. Malang: Universitas Negeri Malang; 2017.

8. Trianto. Mendesain Model Pembelajaran Inovatif Progresif: Konsep, Landasan, dan Implementasinya pada Kurikulum Tingkat 
Satuan Pendidikan (KTSP). Jakarta: Prenada

Media Group; 2013.

9. Amri S. Pengembangan dan Model

Pembelajaran dalam Kurikulum 2013. Jakarta:

PT. Prestasi Pustakaraya; 2013.

10. Lestari DAB, Astuti B, Darsono T.

Implementasi LKS dengan pendekatan

STEM (Science, Technology, Engineering,

and Mathematics) untuk meningkatkan

kemampuan berpikir kritis siswa. J Pendidik

Fis dan Teknol 2018;4(2):202-7.

11. Sayekti AM, Suparman. Deksripsi LKPD

Berbasis PjBL Dengan Pendekatan STEM

untuk Meningkatkan Kemampuan Berpikir

Kritis. In: Prosiding Sendika. Purworejo:

Program Studi Pendidikan Matematika,

Fakultas Keguruan dan Ilmu Pendidikan,

Universitas Muhammadiyah Purworejo; 2019.

12. Sugiyono. Metode Penelitian Kualitatif

Kuantitatif dan R\&D. Bandung: Alfabeta;

2017.

13. Thiagarajan S, Semmel DS, Semmel MI. Instructional development for training teachers of exceptional children. 1974;

14. Departemen Pendidikan Nasional. Panduan

Pengembangan Bahan Ajar. Jakarta: Direktorat Jenderal Manajemen Pendidikan Dasar dan Menengah, Direktorat Pembinaan Sekolah Menengah Atas; 2008.

15. Hamdani A. Pendekatan Akademis

Pendididikan Berbasis Nilai Karakter dan

Budaya Mahasiswa di STIE AUB Surakarta. ProBank [Internet] 2010;1(3). Available from: http://e-journal.stie-aub.ac.id/index.php/ probank/article/view/92

16. Majid A, Rochman C. Pendekatan Ilmiah dalam Implementasi Kurikulum 2013. Bandung: PT. Remaja Rosdakarya; 2013. 